\title{
Does the lung nodule look aggressive enough to warrant a more extensive operation?
}

\author{
Michael Kuan-Yew Hsin, MBBChir, MA, FRCS(CTh), ${ }^{\mathrm{a}}$ and David Chi-Leung Lam, MD, PhD, FRCP ${ }^{\mathrm{b}}$
}

\footnotetext{
From the ${ }^{\mathrm{a} C a r d i o t h o r a c i c ~ S u r g e r y ~ D e p a r t m e n t, ~ Q u e e n ~ M a r y ~ H o s p i t a l, ~ H o n g ~ K o n g ~ S p e c i a l ~ A d m i n i s t r a t i v e ~ R e g i o n, ~}$ China; and ${ }^{\mathrm{b}}$ Division of Respiratory Medicine, Department of Medicine, University of Hong Kong, Hong Kong Special Administrative Region, China.

Disclosures: Authors have nothing to disclose with regard to commercial support.

Received for publication May 26, 2018; revisions received May 26, 2018; accepted for publication May 30, 2018; available ahead of print July 26, 2018.

Address for reprints: Michael Kuan-Yew Hsin, MBBChir, MA, FRCS(CTh), Cardiothoracic Surgery Department,

Queen Mary Hospital, Hong Kong Special Administrative Region, China (E-mail: mkhsin@ hotmail.com).

J Thorac Cardiovasc Surg 2018;156:1667-8

$0022-5223 / \$ 36.00$

Copyright (c) 2018 by The American Association for Thoracic Surgery

https://doi.org/10.1016/j.jtcvs.2018.05.110
}

Early-stage lung cancers often present as lung nodules on computed tomography (CT) scan of the thorax. Radiologic features of lung nodules that suggest malignancy include size, border, shape, and the presence of ground-glass component. However, none of these radiologic features have been found to indicate invasiveness of lung tumor.

Spread through air space (STAS) is a newly described lung cancer histologic pattern. In the current issue of the Journal, Toyokawa and colleagues ${ }^{1}$ report their series of lung cancer surgery with a focus on STAS and preoperative CT images. They showed that whether it was for lobectomy or sublobar resection, the presence of STAS was associated with worse survival outcomes. Tumors without ground-glass opacity (GGO) or those with a notch on CT correlate with STAS on histology. GGO negativity reaffirms previous findings by Shiono and Uruga. ${ }^{2-4}$

The significance of notch positivity pattern on preoperative CT appears novel. The authors ${ }^{1}$ showed that for tumors that were GGO negative or notch positive, the odds ratio for presence of STAS was 2.91. For tumors with both absence of GGO and presence of a notch, the odds ratio for STAS was 5.01. There is a growing body of clinical evidence to support the negative prognostic implication when STAS is present. $^{5-7}$ The phase III JCOG0804 trial $^{8}$ suggested sublobar resections were sufficient for tumors less than $2 \mathrm{~cm}$, with solid tumor ratio less than 0.25 . Toyokawa and colleagues $^{1}$ showed that the presence of STAS was not related to whether the tumor was larger or smaller than $2 \mathrm{~cm}$. Diagnosing STAS preoperatively or even during surgery is challenging. Thus, the presence of a notch on CT could be helpful in selecting patients for lobectomy instead of a sublobar resection.

Notch and GGO are just 2 examples of CT features that could be quantified. The number of notches could be counted and the texture of GGO could be digitalized, and these features may be learned and incorporated into computer algorithms for prediction of invasiveness. 9,10

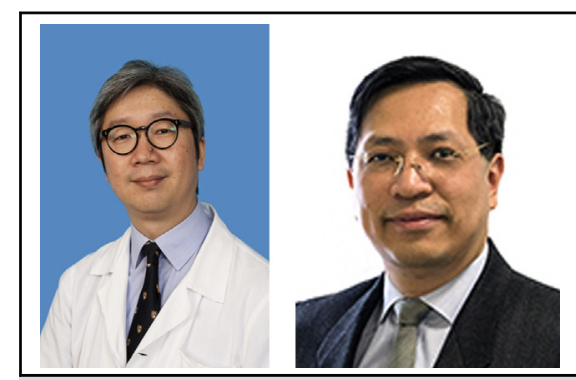

Michael Kuan-Yew Hsin, MBBChir, MA, FRCS(CTh) and David Chi-Leung Lam, MD, PhD, FRCP

Central Message

The radiologic features of notch and GGO for lung nodules correlated with histologic STAS, and this information could guide surgical planning for resection

See Article page 1670 .

Indeed, notch and GGO may not be the only features that are of predictive or prognostic value in lung cancer. ${ }^{11} \mathrm{CT}$ features, including the texture appearance, also could be quantified. $^{12}$ Such quantitative parameters could be correlated in a linear and proportional fashion to the growth rate of tumor and even correlated with genomic characteristics, such as the presence of epidermal growth factor receptor mutations. ${ }^{13}$

Toyokawa and colleagues ${ }^{1}$ clearly demonstrated the importance of integration among clinical, pathologic, and radiologic features. Further prospective evaluation and validation of the CT associations with STAS are warranted. Imaging phenotypes such as the presence of a notch or GGO may serve as surrogates for underlying tumor invasiveness. The presence of STAS or its representation by a notch on CT could be further evaluated as a marker for deep learning for formulations of computer algorithms that will pave the way for the application of artificial intelligence in predicting invasiveness of lung tumor, ultimately helping clinicians to stratify lung cancers and to select the appropriate surgical resection.

\section{References}

1. Toyokawa G, Yamada Y, Tagawa T, Kamitani T, Yamasaki Y, Shimokawa M, et al. Computed tomography features of resected lung adenocarcinomas with spread through air spaces. J Thorac Cardiovasc Surg. 2018;156:1670-6.

2. Shiono S, Yanagawa N. Spread through air spaces is a predictive factor of recurrence and a prognostic factor in stage I lung adenocarcinoma. Interact Cardiovasc Thorac Surg. 2016;23:567-72. 
3. Uruga H, Fujii T, Fujimori S, Kohno T, Kishi K. Semiquantitative assessment of tumor spread through air spaces (STAS) in early-stage lung adenocarcinomas. J Thorac Oncol. 2017;12:1046-51.

4. Yanagawa N, Shiono S, Endo M, Ogata SY. Tumor spread through air spaces is a useful predictor of recurrence and prognosis in stage I lung squamous cell carcinoma, but not in stage II and III. Lung Cancer. 2018;120:14-21.

5. Kadota K, Kushida Y, Katsuki N, Ishikawa R, Ibuki E, Motoyama M, et al. Tumor spread through air spaces is an independent predictor of recurrence-free survival in patients with resected lung squamous cell carcinoma. Am J Surg Pathol. 2017; 41:1077-86.

6. Warth A. Spread through air spaces (STAS): prognostic impact of a semi-quantitative assessment. J Thorac Dis. 2017;9:1792-5.

7. Morimoto J, Nakajima T, Suzuki H, Nagato K, Iwata T, Yoshida S, et al. Impact of free tumor clusters on prognosis after resection of pulmonary adenocarcinoma. J Thorac Cardiovasc Surg. 2016;152:64-72.e1.

8. Suzuki KW, Watanabe S, Wakabayashi M, Moriya Y, Yoshino I, Tsuboi M, et al. A nonrandomized confirmatory phase III study of sublobar surgical resection for peripheral ground glass opacity dominant lung cancer defined with thoracic thin-section computed tomography (JCOG0804/WJOG4507L). J Clin Oncol. 2017;35(15 Suppl):8561 [Abstract].

9. Ma J, Zhou Z, Ren Y, Xiong J, Fu L, Wang Q, et al. Computerized detection of lung nodules through radiomics. Med Phys. 2017;44:4148-58.

10. Vardhanabhuti V, Kuo MD. Lung cancer radiogenomics: the increasing value of imaging in personalized management of lung cancer patients. J Thorac Imaging. 2018;33:17-25.

11. Song J, Liu Z, Zhong W, Huang Y, Ma Z, Dong D, et al. Non-small cell lung cancer: quantitative phenotypic analysis of CT images as a potential marker of prognosis. Sci Rep. 2016;6:38282.

12. Lee G, Lee HY, Park H, Schiebler ML, van Beek EJR, Ohno Y, et al. Radiomics and its emerging role in lung cancer research, imaging biomarkers and clinical management: state of the art. Eur J Radiol. 2017;86:297-307.

13. Hong SJ, Kim TJ, Choi YW, Park JS, Chung JH, Lee KW. Radiogenomic correlation in lung adenocarcinoma with epidermal growth factor receptor mutations: imaging features and histological subtypes. Eur Radiol. 2016;26:3660-8. 